\title{
IDEIAS PEDAGÓGICAS DE UMA SOCIOLOGIA CRISTÃ: NOTAS SOBRE UM COMPÊNDIO [1] DE SOCIOLOGIA DA DÉCADA DE 1940 [2]
}

\author{
Marcelo Pinheiro Cigales* \\ Universidade Federal de Pelotas - UFPel
}

\section{RESUMO}

No início do século XX, a institucionalização da sociologia no Brasil foi marcada por uma quantidade considerável de manuais e compêndios produzidos para o ensino da disciplina. Esse período ficou caracterizado pela diversidade teórica que influenciou a escrita dos intelectuais brasileiros, empenhados na realização dessa tarefa. Nesse sentido, o objetivo do presente artigo é analisar o manual de sociologia denominado "Programa de Sociologia" de Afro do Amaral Fontoura publicado em 1940. Esse livro foi escrito com o intuito de servir para o Programa oficial da cadeira de sociologia na escola secundária, visto a obrigatoriedade da disciplina nessa modalidade de ensino na época. O referencial teórico-metodologico está embasado na História das Disciplinas Escolares e na Análise Documental. Entre os principais resultados encontrados, podemos apontar a relação entre as ideias de Amaral Fontoura com as premissas da chamada "Sociologia Cristã", escola sociológica ligada ao pensamento da Igreja Católica e de seus postulados.

Palavras-chave: Afro do Amaral Fontoura, manuais de sociologia, Sociologia Cristã.

\section{IDÉES PEDAGOGIQUES D’UNE SOCIOLOGIE CRÊTE: NOTES SUR UN COMPENDIUM DE SOCIOLOGIE DU DECENNIE 1940}

\section{RESUME}

Dans le début du siècle $\mathrm{XX}, 1^{\prime}$ institutionnalisation de la sociologie au Brésil a été marqué par une quantité considérable de Manuels et compendium produits pour l'enseignement de la discipline. Cette période a été resté caracterisée par une diversité théorique qui influenciais l'écriture des intellectuels brésiliens, engagés dans la réalisation de cet devoir. Dans ce sens, 1' objetif du présent article est analysé le Manuel de sociologie dénommé "Programme de Sociologie" de Afro do Amaral Fontoura publié em 1940. Ce livre a été écrit avec l'intention de servir pour le Programme officiel d'une chaise de sociologie dans l'école sécondaire, vue l'obligation de la discipline dans cette modalité d'enseignement dans cette époque. La référence théorique-méthodoligique est basée dans $1^{\prime}$ histoire des Disciplines scolaires et dans 1' analyse de Document. Entres les principaux résultats trouvés, pouvons indiquer la relation entre les idées de Amaral Fontoura avec les prémisses d'appelle “Sociologie Crête”, école sociologie liée au pensée de 1' Église Catholique et de ses postulats.

Mots- clés : Afro do Amaral Fontoura, Manuel de sociologie, sociologie Crête 


\section{Introdução}

Os manuais e compêndios de sociologia utilizados para o ensino da disciplina na educação brasileira é um tema que vem despertando o interesse de pesquisadores na área de história da sociologia no Brasil. Os trabalhos de Simone Meucci (2000; 2005; 2007) Flávio Sarandy (2004) e Eliane Perez (2002) refletem esse interesse em analisar a sociologia por meio dos manuais. Apesar disso, é possível afirmar que ainda existe muito trabalho a ser feito, visto a complexidade e quantidade de manuais de sociologia produzidos ainda no início do século XX.

Nesse período a sociologia como disciplina escolar esteve presente, ainda que intermitente, nos três níveis de ensino: secundário, normal e superior. Por se tratar de uma ciência relativamente jovem, houve no Brasil, uma facilidade na produção de livros e manuais de ensino atrelados a concepções teóricas diversas. Dessa forma, surgiram algumas escolas sociológicas, entre elas a chamada "Sociologia Cristã", ligada aos pressupostos da Igreja Católica.

Este trabalho tem por objetivo descrever e analisar, ainda que suscintamente, o manual de Afro do Amaral Fontoura, denominado "Programa de Sociologia" utilizado para o ensino da disciplina no ensino secundário. Esse manual de sociologia foi publicado pela primeira vez em 1940, alcançando a quarta edição em 1944, como apresentado pela editora "Biblioteca Didática Brasileira" na capa de outro manual do mesmo autor. (FONTOURA, 1957).

A metodologia desenvolvida nessa pesquisa esta embasada na análise documental, sobre esse método Ludke e Menga (1986, p. 38) ressaltam que "embora pouco explorada não só na área de educação como em outras áreas de ação social, a análise documental pode se constituir numa técnica valiosa de abordagem de dados qualitativos".

Em relação ao enfoque teórico, a pesquisa busca base na perspectiva teórica da História das Disciplinas Escolares. Para Junior e Galvão (2005, p. 393), no campo da HDE é possível captar elementos que "em um conflituoso percurso de conquista de legitimidade de uma ou outra disciplina curricular, mostrem a conquista de um estatuto, a briga por recursos, as delimitações territoriais no interior do currículo escolar, os espaços nos horários, etc".

Nesse sentido Bittencourt (2003) também salienta que ao analisar uma disciplina escolar é importante que se busque perceber as lutas e esforços que determinados grupos, partidos e associações fazem para que determinada disciplina consiga ascender e permanecer no currículo escolar. A HDE também se interessa em estudar o papel que desempenha o livro didático no interior do sistema educacional. Nesse sentido, Viñao (2008) salienta a importância de pensar as disciplinas escolares para além dos conteúdos, visto que o livro didático é um valioso material que guarda, através do tempo, resquícios de ideias e valores de grupos sociais distintos.

Outros autores, como Choppin (2004) e Magalhães (2006) também ressaltam a importância da história do livro didático e sua relevância para a história da educação. $\mathrm{O}$ primeiro autor, chama a atenção do poder que o livro escolar vem exercendo na economia editorial dos últimos dois séculos, um exemplo é o Brasil em que os livros didáticos "correspondiam, no início do século $\mathrm{XX}$, a dois terços dos livros publicados e representavam, ainda em 1996, aproximadamente a $61 \%$ da produção nacional" (CHOPPIN, 2004, p. 551). Ainda conforme o autor os livros didáticos exercem quatro funções: função referencial; função instrumental; função ideológica e cultural, e, função documental. A primeira refere-se a tradução do programa da disciplina e tem o objetivo de transmitir o suporte técnico e científico de uma geração a outra. Na segunda função o livro didático põe em prática métodos de aprendizagem, se propõe a realização de exercícios e 
atividades, é mais prático e objetiva a aquisição de competências disciplinares e transversais. A terceira função apontada por Choppin (2004) é a mais antiga, pois com a constituição dos estados nacionais e com o "desenvolvimento, nesse contexto, dos principais sistemas educativos, o livro didático se afirmou como um dos vetores essenciais da língua, da cultura e dos valores." (2004, p. 553). Essa função pode ocorrer tanto de maneira implícita como dissimulada, tendo por objetivo aculturar valores nacionais e criar o senso de patriotismo nas gerações que estão se escolarizando.

Tendo este referencial por base, este estudo busca contribuir com as pesquisas históricas e sociológicas sobre o ensino da disciplina de sociologia na educação brasileira, apresentando um autor ainda pouco conhecido como salientam Maciel, Vieira e Souza (2012).

Afro do Amaral Fontouro, nasceu em 1912, "formou-se em magistério e foi professor nos cursos Normais do Rio de Janeiro quando publicou o seu primeiro manual. Alguns anos depois, já formado [...], passou a dar aulas de sociologia e serviço social nas principais faculdades fluminenses". (MEUCCI, 2000, p. 43-44). Apesar de ter escrito diversos livros sobre pedagogia, sociologia e outros assuntos ligados ao ensino, ainda são raras as pesquisas sobre a vida de Amaral Fontoura, bem como de sua relevância para o desenvolvimento do ensino da sociologia no país.

Alceu Amoroso Lima na introdução do "Programa de Sociologia" ressalta: "seu autor, embora ainda esteja cursando a Faculdade Nacional de Filosofia, já foi Diretor e é professor de estabelecimento de ensino secundário e tem grande prática de ensino". (FONTOURA, 1944, p. 13). Esse fato demostra que assim como outros autores dos primeiros manuais de sociologia do país, Amaral Fontoura era um escritor auto-didata em Sociologia. No entanto, pelas referências bibliográficas apresentadas no livro, é possível afirmar que Fontoura conhecia autores como Émile Durkheim, Karl Marx, Spencer, August Comte, etc, além de uma ampla literatura sobre os autores brasileiros que escreviam sobre sociologia, como Fernando de Azevedo, Pontes de Miranda, Pinto Ferreira, Delgado de Carvalho, etc.

O manual elaborado por Amaral é extenso, porém os assuntos nele tratados são introdutórios e sucintos. O autor também se dedicou a escrita de mais dois manuais voltados ao ensino da sociologia: "Introdução à Sociologia" de 1948 e "Sociologia Educacional" de 1951.

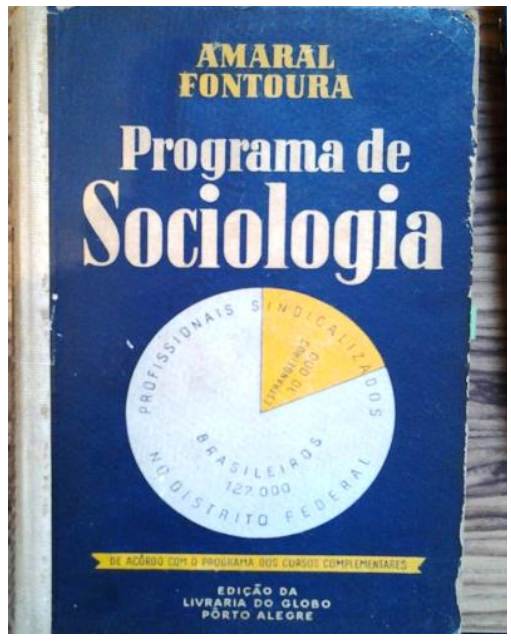

Fig. 01. Programa de Sociologia, 1944, $4^{\text {a }}$ edição.

Fonte: Aquivo Pessoal

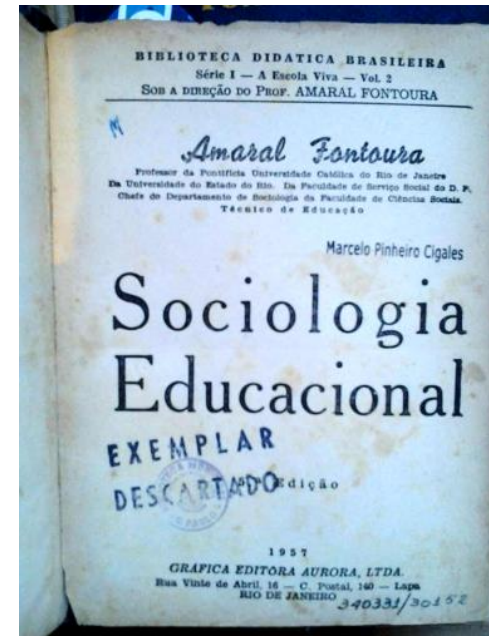

Fig. 02. Sociologia Educacional, $1957,5^{\text {a }}$ edição

Fonte: Arquivo Pessoal

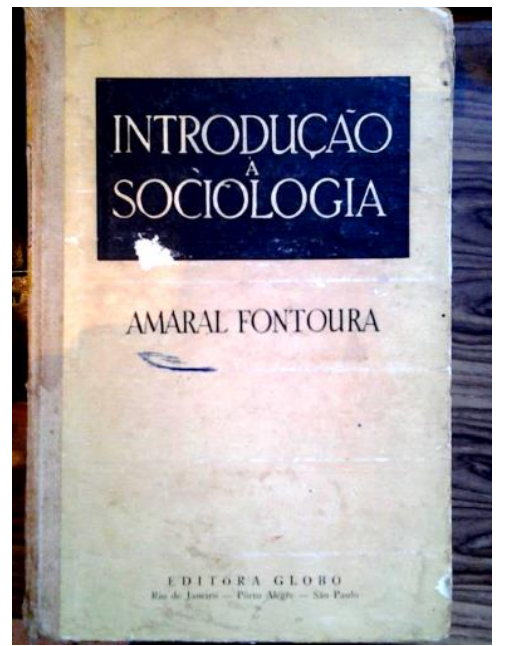

Fig. 03. Introdução à Sociologia, 1961, $3^{\text {a }}$ edição

Fonte: Arquivo Pessoal 
"Introdução à Sociologia" foi um aprofundamento do "Programa de Sociologia", com o objetivo de direcionar o livro ao ensino superior. "Resolvemos aproveitar a oportunidade e fazer uma reestruturação geral em nosso livro, surgindo assim esta Introdução à Sociologia". (FONTOURA, 1961, Prefácio). Já o livro "Sociologia Educacional" foi um trabalho voltado aos cursos normais, modalidade de ensino responsável pela formação de professores.

Além dessas três obras, o autor escreveu "Fundamentos de Educação" de 1949, "Metodologia do Ensino Primário" de 1955, "Psicologia Geral" de 1957, "O ruralismo, Base da Economia Nacional" de 1941, "Dicionário Enciclopédio Brasileiro" de 1943, "O drama do campo" de 1949, "Introdução ao Serviço Social" de 1950, "Aspectos da vida Rural Brasileira" de 1950, e "Atualidade Política Brasileira à Luz da Sociologia" de 1955.

Ainda estavam em preparo conforme a capa de divulgação de suas obras impresso junto ao livro "Sociologia Educacional" de 1957, "Retrato Verdadeiro do Brasil", "Tratado de Sociologia Rural Brasileira", "Organização da Comunidade", "Educação de Base e Centros Sociais Rurais" e, "O drama da Criança". Essa amplitude de temas não era uma característica apenas do autor, outros autores como Delgado de Carvalho (MEUCCI, 2000) também se dedicaram a escrita de vários manuais. Esse fato decorreu da demanda por escritores, principalmente por autores de livros didáticos no início do século XX.

\section{PROGRAMA DE SOCIOLOGIA (1944): CONSIDERAÇÕES INICIAIS}

A quarta edição do livro "Programa de Sociologia", ao qual se realizará a análise, foi publicado em 1944 pela Livraria do Globo de Porto Alegre. O livro está dividido em 44 pontos ou capítulos, somando um total de 443 páginas [3]. Além disso, contém uma introdução de Alceu Amoroso Lima e uma carta-prefácio de Jacques Lambert, professor catedrático da Faculdade de direito de Lyon na França.

Alceu Amoroso Lima, foi um intelectual católico responsável pela divulgação da sociologia cristã no Brasil. Conforme Saviani (2010), Amoroso Lima,

[...] converteu-se ao catolicismo em 1928 por influência de Jackson de Figueiredo. Com a morte deste, assumiu a direção da revista A Ordem e do Centro Dom Vital. Daí em diante, com destaque especial para as décadas de 1930 e 1940, animou o movimento leigo da Igreja, podendo ser considerado o maior líder intelectual católico do século XX no Brasil. (SAVIANI, 2010, p. 256).

Também conhecido pelo pseudônimo de Tristão de Athayde, Alceu Amoroso Lima escreveu "Preparação à Sociologia" $2^{a}$ edição em 1942. Também "publicou grande número de artigos criticando contundentemente o 'Manifesto' e o grupo responsável pelo seu lançamento" (SAVIANI, 2010, p. 254)". O grupo ao qual se refere Saviani corresponde aos "Renovadores da Educação", tendo entre os principais representantes Fernando de Azevedo, líder do grupo que publicou o Manifesto dos Pioneiros da Educação Nova no iníco da década de 1930. Esse documento foi assinado por uma série de intelectuais que pretendiam ver garantida na Constituição seus ideais, como o direito da educação laíca, gratuíta e de qualidade.

$\mathrm{Na}$ introdução do livro "Programa de Sociologia", Amoroso Lima afirma, "este livro é um compêndio e só isso pretende ser" (FONTOURA, 1944, p. 13). Esta delimitação mais adiante é reafirmada por Amaral Fontoura "este livro nada de inédito contém em 
matéria sociológica [...] nosso intuito foi fazer um compêndio que servisse ao programa oficial da cadeira". (FONTOURA, 1944, p. 15). Dessa forma, os mais variados temas perpassam o manual de sociologia, entre eles podemos citar a própria formação da sociologia e definição do campo sociológico; a família; o feminismo; a educação; a Igreja e o Estado, sempre marcados pelo conservadorismo da concepção católica de sociologia.

Para Amaral Fontoura a sociologia não poderia se restringir ao conteúdo normativo, era uma ciência viva e, portanto deveria ser ativa. "Sociologia é matéria viva, Sociologia é vida. Fazemos sociologia em casa, na repartição, na escola, no clube, na igreja [...] o ensino da sociologia ou é ativo, vivo, ou não é ensino de sociologia". Acrescenta também que "não se aceita mais, em ciência nenhuma, a figura antipedagógica do professor falasozinho, do mestre-disco-de-gramafone a repetir o ano inteiro aquilo que esta escrito nos compêndios" (FONTOURA, 1944, p. 16). Nesse sentido é possível perceber na obra do autor uma tendência da Escola Nova.

Para Bomeny (2003),

A Escola Nova, inspirada em grande medida nos avanços do movimento educacional norte-americano, mas também de outros países europeus, teve grande repercursão no Brasil. Os ideias que lhe deram corpo foram sempre inspirados na concepção de aprendizagem do aluno por si mesmo, por sua capacidade de observação, de experimentação, tudo isso orientado e estimulado por profissionais da educação que deveriam ser treinados especialmente para esse fim. Duvidando dos métodos convencionais, acabava questionando toda uma maneira convencional do agir pedagógico. O Movimento da Escola Nova no Brasil se empenha em questionar diretamente a dispersão dos acontecimentos, a fragmentação, a forma como se condiziu a educação no Brasil do início da República. Mas o próprio movimento reflete essa fragmentação [...] Transitavam entre os educadores as interpretações mais variadas das correntes e doutrinas pedagógicas sob a mesma sigla genérica de Escola Nova ou Educação Nova. (BOMENY, 2003, p. 43-44).

De certa forma nesse período no Brasil quase todas as correntes teóricas que abordavam a pedagogia estavam de acordo com a modernização proposta pela Escola Nova, embora algumas fossem conservadoras, ou seja, não praticavam aquilo que pregavam.

Além da introdução de Alceu Amoroso Lima e da carta-prefácio de Jacques Lambert, o livro conta com mais três participações. A primeira é de autoria de Silvio Júlio, refere-se a um capítulo denominado "A sociologia na América Latina". Em um breve comentário Amaral Fontoura apresenta o autor,

O Programa de Sociologia tem a honra de apresentar o presente capítulo escrito especialmente para êste livro por Silvio Júlio. Catedrático de História da América da Universidade do Brasil é, sem dúvida nenhuma, o maior americanista brasileiro. Colocando ao alcance da mocidade estudiosa de nosso país um resumo do Movimento Sociológico HispanoAmericano, assunto que pela primeira vez aparece publicado em livro didático escrito em português, Silvio Júlio presta assim mais um assinalado serviço à causa da Cultura da America. (FONTOURA, 1944, p. 86). 
Também participaram do livro, Fábio Luiz Filho, "uma das maiores figuras do cooperativismo brasileiro" (FONTOURA, 1944, p. 294) que escreveu um texto sobre "O cooperativismo no Brasil". E, o jovem Luiz Aguiar Costa Pinto [4], com o texto "Organização Econômica do Brasil - Esboço". O texto de Costa Pinto, ainda aluno do curso complementar de Direito na época, foi vencendor do Concurso de Sociologia Brasileira, realizado em 1939, como apresenta Fontoura (1944, p. 308).

\section{A SOCIOLOGIA CRISTÃ: LINHA MESTRA DA OBRA}

Na classificação das escolas sociológicas Amaral Fontoura distingue 11 vertentes, entre elas está a Escola Cristã ou Integral da Sociologia. Para o autor, a Sociologia Cristã, "distingue no homem dois aspectos: o indivíduo e a pessoa. Como indivíduo, o homem é igual a todos os demais sêres vivos e está subordinado ao mesmo determinismo da natureza. Mas como pessoa, o homem possue uma alma imortal [...] não obedecendo senão a Deus". (FONTOURA, 1944, p. 53). Mais adiante ressalta que "a sociologia cristã se chama integral porque considera, na análise dos fenômenos sociais, os fatores naturais e os sobrenaturais, mostrando a impossibilidade do mundo terrestre viver em paz e harmonia quando esquece o Criador e suas leis". (FONTOURA, 1944, p. 53).

Em defesa dessa sociologia, Tristão de Athayde ressalta que diferentemente das outras escolas sociológicas a sociologia cristã deixava claro quais eram seus postulados $[5]$,

[...] nós, partidários de uma sociologia finalista e integral, apresentamos explicitamente quais os postulados da sociologia cristã [...] a) a existência de Deus; b) a imortalidade da alma; c) a liberdade da vontade; e d) a encarnação de Cristo. Se confrontarmos uns e outros postulados, êstes confessados, - se bem que nem sempre expressos nessa fórmula, que me parece clara e explícita, mas que absolutamente não é a única nem será a definitiva - e aqueles quase sempre inconfessados, vemos bem nítida uma finalidade transcendental que completa a realidade imanente, e a sociologia naturalista, em suas inúmeras modalidades que se satisfaz com o fenomenismo materialista ou agnóstico. [...]. Eis porque motivo não hesito em proclamar que a sociologia cristã é a mais elevada, a mais científica e a mais completa das concepções sociológicas. (ATHAYDE, 1942, p. 30-31).

Para Meucci (2001, p. 126) essa corrente teórica "era de origem francesa representada por pensadores conservadores católicos como Le Play e, principalmente Jacques Maritain". Dessa forma Alceu Amoroso Lima [Tristão de Athayde], Francisca Peters, Guilherme Boing, Amaral Fontoura e Severino Sombra estão, conforme a autora, entre os organizadores que difundiam entre nós a chamada "Sociologia Cristã". Desse modo, a sociologia era compreendida "[...] como uma área de conhecimento que se dedicava, por um lado, à investigação da vida social e, por outro, à instituição de padrões de conduta cristãos adequados à conservação do equilíbrio social" (MEUCCI, 2001, p. 126). Consequentemente a concepção cristã de sociologia, irá influenciar o pensamento do autor na escrita do livro, e na percepção de temas como a família, o papel da mulher e o feminismo.

Para Amaral Fontoura, existiam papéis que o marido e a mulher deveriam cumprir no interior da família. O homem era considerado o cabeça, o responsável legal do grupo 
familiar. Dessa forma era dever do marido “a) representação legal da família e administração dos seus bens; b) fixação e mudanças do domicílio, bem como autorização da profissão da mulher; c) obrigação de prover ao sustento da família e custear a educação dos filhos." (FONTOURA, 1944, p. 152). Em relação a mulher, Amaral Fontoura afirmava que com o casamento esta deveria "a) usar o nome do marido; b) zelar pela boa administração interna do lar; c) auxiliar o marido nos encargos de família, sempre que assim se fizer necessário; d) substituir o marido nos seus impedimentos. (1944, p. 152153). Adiante ressalta que, "a êsses deveres da espôsa se acrescenta até há pouco tempo o da obediência cega ao marido. Hoje em dia essa obediência é menos inconsciente e varia, geralmente, com o nível da mentalidade feminina [...]" (1944, p. 153).

Sobre o feminismo Fontoura afirma que é um direito natural da mulher, porém esta não deve, de maneira alguma ocupar os postos de trabalho do homem. Assim, o feminismo:

[...] é dos mais cruciantes problemas da sociologia doméstica contemporânea. No passado, como vimos examinando, tal problema não existia, porque sempre e por toda a parte a mulher era apenas uma semiescrava do marido. [...] $\mathrm{O}$ feminismo, portanto, não é nem novo nem discutível: é um direito natural da mulher. Se não tem ocupado posições de rêlevo na história da humanidade, é exatamente porque os homens não lho permitiam. [...] examinemos outra face do problema; o trabalho feminino. Regra geral, êle é um mal, porque afasta a mulher do pôsto que naturalmente lhe compete na engrenagem social: a direção do lar. Não há organização perfeita onde não há divisão de trabalho e especialização de funções. [...] Agora outro aspecto ainda: o feminismo integral leva as mulheres a concorrer em todo o terreno com o homem, tomando muitas vezes o emprêgo de um chefe de numerosa família. (FONTOURA, 1944, p. 158).

Dessa forma, o autor acrescenta que "o feminismo integral deve, pois, ser combatido, para o perfeito equilibrio social”. (1944, p. 159).

Em relação à laicidade do ensino, Fontoura (1944, p. 355) é enfatico ao descrever que "a escola sem o conhecimento de Deus é uma utopia, é uma maneira capciosa de apresentar o problema, porque desconhecer Deus é negá-lo. A escola laica não é a escola sem Deus: é a escola contra Deus". Esta ligação do ensino com as premissas da Igreja Católica, e consequentemente com o ensino privado irá despertar um conflito, principalmente após a divulgação do Manifesto dos Pioneiros da Educação Nova em 1932.

\section{POR UM ENSINO LAÍCO, GRATUÍTO E DE QUALIDADE}

A concepção sociológica cristã se contrapõe as ideias educacionais apregoadas pelos intelectuais ligados ao movimento da Escola Nova. Conforme Cury (1987), no campo educacional, apesar dos debates pedagógicos antecederem a Revolução de Trinta, eles só adquirem contornos nítidos de propostas quando se aproxima a oportunidade de, através da elaboração da constituição de 1934, os diversos grupos envolvidos nestes debates concretizarem constitucionalmente a consagração de suas ideias.

Essa concepção de sociologia surgiu no Brasil, possivelmente, devido ao movimento levado a cabo pela Igreja Católica na Europa entre fins do século XIX e início do século XX. Como ressalta Serry (2004), a Igreja e seus intelectuais se mobilizaram 
entre 1880 e 1930 diante do surgimento da sociologia como disciplina científica. Para o clero e seus intelectuais, a escola de Durkheim era controversa. Tratava-se de uma oposição que buscava criar uma sociologia católica, com base na filosofia tomista, que, nesse momento, orientava a doutrina social da Igreja, a fim de não perder a explicação do mundo social para aqueles que se opunham às doutrinas apregoadas por essa instituição. Para o autor, a argumentação teórica e política desenvolvida pelos defensores da sociologia católica - entre eles, herdeiros de Frédéric Le Play - é, ainda hoje, pouco pesquisada (SERRY, 2004).

Como demonstrou Miceli (2009), a Igreja Católica no Brasil buscou fortalecer-se após separar-se do Estado no final do século XIX. Assim, houve a criação de dioceses em diversos estados brasileiros. No campo educacional, a criação de diversas escolas para atender ao ensino primário, secundário e normal foi reflexo da expansão dessa instituição. Assim como a produção dos manuais escolares, o investimento em editoras representou um avanço para essa instituição, que poderia abastecer suas entidades educacionais com materiais didáticos produzidos por seus próprios intelectuais.

Ao analisar os manuais de sociologia produzidos nessa época é possível perceber que poucos foram escritos por autores formados em sociologia. A maior parte foi elaborada por intelectuais engajados em assuntos educacionais, caso por exemplo de Fernando de Azevedo, Carneiro Leão e Alceu de Amoroso Lima. Dessa forma, "Os educadores e os chamados pensadores conservadores são, nos anos 30, os dois grandes grupos de especialistas aptos a responderem a essa demanda editorial. E mais, a fixarem, através de complexas análises sobre a organização política e social do Brasil [...]. (PONTES, 1989, p. 370).

Por meio da análise dos manuais elaborados pelos intelectuais ligados a Igreja Católica é possível identificar a legitimação de uma sociologia que se enquadrasse nos princípios cristãos. Certamente assuntos como a existência de Deus, o feminismo integral (aquele que defende espaços iguais no mercado de trabalho para a mulher) e a importância da Igreja Católica, foram tratados em tais compêndios de sociologia voltados ao ensino da disciplina nos colégios confessionais (CIGALES, 2014).

\section{CONSIDERAÇÕES FINAIS}

Sem a pretensão de esgotar as possibilidades de análise do livro "Programa de Sociologia" de Amaral Fontoura, esta pesquisa visou contribuir para a história do ensino da disciplina no Brasil. Através de uma leitura do compêndio, foi possível evidenciar alguns temas utilizados no ensino da disciplina na década de 1940. Entre eles, a classificação das escolas sociológicas, a divisão entre os papéis do homem e da mulher no interior da família, o feminismo e a educação cristã.

Podemos considerar que a sociologia, por ser fruto do final do século XIX e início do século $\mathrm{XX}$, permitiu que diferentes grupos vinculassem suas ideias na roupagem da sigla "sociologia", considerada uma ciência explicativa para os problemas sociais. Desse modo, pode ter surgido no Brasil uma diversidade de "escolas sociológicas", tal como a "sociologia cristã".

Certamente a análise dos manuais de sociologia para o ensino da disciplina no Brasil, é importante para compreendermos como ocorreu a institucionalização da sociologia no país, pois através deles é possível perceber a existência de "grupos sociais com interesses divergentes e com postulações ideológicas e culturais heterogêneas" no qual a constituição do campo disciplinar e consequentemente sua institucionalização no 
ensino, pode ter gerado uma série de disputas "políticas" e "simbólicas". (FORQUIN, 1992).

Essa possibilidade de associação de determinadas ideias com a sociologia, de certa forma, respondia a necessidade de cada grupo explicar os problemas sociais a partir de sua visão de mundo. Possivelmente esse fato influenciou o ensino da disciplina na educação brasileira, tendo a sociologia, assim como a produção de manuais voltados ao seu ensino, sofrido a influência dessa diversidade de "escolas sociológicas" com destaque para a vertende cristã, analisada neste trabalho através dos livros de Fontoura (1944) e Athayde (1942). Este grupo em especial, tinha na época diversas instituições educacionais, onde a criação de uma disciplina como a sociologia, requeria uma produção de livros e materiais para seu ensino específica, ou seja, possivelmente autores críticos ou contrários as premissas da Igreja Católica, principalmente ao ensino privado, não estavam em circulação nas escolas confessionais.

\section{ANEXO}

\section{1. Índice Geral do Livro "Programa de Sociologia" de Amaral Fontoura-1944}

Carta-prefácio do Professor Jacques Lambert;

Introdução - Prof. Alceu Amoroso Lima;

Didática da Sociologia (ligeiras observações);

Ponto 1- Sociologia, conceito e definição;

Ponto 2- Objeto da Sociologia. Fato Social;

Ponto 3- Esbôço histórico da Sociologia;

Ponto 4- Relação da Sociologia com as ciências conexas;

Ponto 5- Metodologia Sociológica;

Ponto 6- Escolas positivista, evolucionista, socialista. Escola de Durkheim;

Ponto 7- Escolas de reforma social, ciência social, histórico-cultural;

Ponto 8- Sociólogo norte-americano, brasileiros e latino-americanos;

Ponto 9- Exposição geral do problema da formação dos grupos sociais primitivos;

Ponto 10- Teorias sôbre a formação da família. Matriarcado, patriarcado, monogamia e poligamia;

Ponto 11- As origens sociais à luz da etnologia moderna. A tese de Durkheim e a doutrina da História Cultural;

Ponto 12- A propriedade entre os povos primitivos;

Ponto 13- A religião entre os povos primitivos;

Ponto 14- A lei moral e os primitivos;

Ponto 15- Ciências especulativas e normativas. Moral e sociologia. Levy-Bruhl e Simon Deploige;

Ponto 16- Postulados da Sociologia;

Ponto 17- Tipos de família. Evolução histórica. A família moderna;

Ponto 18- O casamento. Direitos e deveres dos cônjuges;

Ponto 19- Importância moral e social da família. Eugenismo. Feminismo;

Ponto 20- Da propriedade. Seu fundamento e sua origem;

Ponto 21- Natureza do direito a propriedade. Seus limites. Teorias contra a propriedade;

Ponto 22- Sociedade. Elementos constitutivos. Sua classificação. Princípios fundamentais do convívio humano; 
Ponto 23- O homem e o ambiente social. Influência dos fatores geográficos, biológicos, econômicos, etc;

Ponto 24- Sociedade política. Nação e Estado. Seus elementos;

Ponto 25- Origem do Estado. Diversas teorias a respeito;

Ponto 26- Formas do Estado. Teorias de Aristóteles, Maquiavel e Montesquieu. Estado unitário e composto;

Ponto 27- Governo representativo. Sufrágio universal;

Ponto 28- Grupos e classes sociais. Psicologia política. Luta e cooperação de classes.

Ecologia social;

Ponto 29- Regime constitucional. Estado corporativo. Ditadura;

Ponto 30- Órgãos e funções do Estado. Teorias da divisão de poderes;

Ponto 31- Direitos e deveres do Estado. Sua extensão;

Ponto 32- Garantia dos direitos individuais. Liberdades públicas;

Ponto 33- O direito. Direito natural, costumeiro e positivo. Direito e moral. Divisão do direito. Hierarquia das leis;

Ponto 34- O direito internacional. Relações entre os Estados na paz e na guerra. Sociedade das Nações;

Ponto 35- Organizações econômicas da sociedade. O trabalho. Espécies. Dignidade e valor do trabalho;

Ponto 36- Papel do trabalho na produção. As máquinas. Trabalho feminino. Conflitos de trabalho. Legislação social;

Ponto 37- Remuneração do trabalho. O salário. O salário mínimo. O desemprêgo e a assistência do Estado;

Ponto 38- Associações profissionais. Sindicatos. Representação profissional. Cooperativismo;

Ponto 39- O capital. Regime capitalista. Abusos do capital;

Ponto 40- A Igrela e o Estado. Influência social da religião;

Ponto 41- Intrução e educação. Liberdade de ensino. Ensino religioso e ensino leigo;

Ponto 42- Valor da educação para o progresso social. A estrutura do ensino. Obrigatoriedade e gratuidade escolar;

Ponto 43- O problema da população e a teoria de Malthus. Imigração, colonização, povoamento. Reinindicação de espaço;

Ponto 44- Sociologia criminal. O crime e a pena. Responsabilidade. Causas do crime. Estatística criminal.

Apêndice - I) Modêlo de testes a empregar;

Apêndice - II) Relação de tôdas as questões de exame pedidas no Vestibular das várias Faculdades da Universidade do Brasil, no ano de 1940.

Bibliografia geral, por assunto;

Índice detalhado por assuntos;

Índice dos nomes citados;

Algumas referências sobre o "Programa de Sociologia".

\section{Referências}

ATHAYDE, Tristão de. Preparação à Sociologia. 2. ed. Rio de Janeiro: Editora Getúlio Vargas, 1942. 
BOMENY, Helena. Os intelectuais da educação. 2. ed. Rio de Janeiro: ZAHAR, 2003.

BOURDIEU, Pierre; PASSERON, Jean-Claude. A Reprodução: elementos para uma teoria do sistema de ensino. Petrópolis, RJ: Vozes, 2008.

BOURDIEU, Pierre. O Poder Simbólico. 16. ed. Tradução de Fernando Tomaz. Rio de Janeiro: Bertrand Brasil, 2012.

BITTENCOURT, C. M. F. Disciplinas escolares: história e pesquisa. In OLIVEIRA, M. A. T. de; RANZI, S. M. F. (orgs.). História das disciplinas escolares no Brasil: contribuições para o debate. Bragança Paulista: EDUSF, 2003.

CIGALES, Marcelo Pinheiro. A sociologia educacional no Brasil (1946-1971): análise sobre uma instituição de ensino católica. 2014. 150f. Dissertação (Mestrado em Educação) - Programa de Pós-gradução em Educação, Instituto de Ciências Humanas, Universidade Federal de Pelotas, Pelotas, 2014.

CHOPPIN, Alain. História dos livros e das edições didáticas: sobre o estado da arte. Educação e Pesquisa. v. 30, n. 3, p. 549-566, 2004.

CURY, Carlos R. Jamil. Ideologia e educação brasileira: católicos e liberais. 3. ed. São Paulo: Cortez \& Moraes, 1978. (Coleção Educação Universitária).

FERREIRA, Aurélio B. de Hollanda. Aurélio: o dicionário da língua portuguesa. (edição especial). 2. ed. Curitiba: Positivo, 2008.

FORQUIN, Jean-Claude. Saberes escolares, imperativos didáticos e dinâmicas sociais. Teoria \& Educação, n. 5. p. 28-49, 1992.

FONTOURA, Afro do Amaral. Programa de Sociologia. Porto Alegre: Globo, 1944.

Sociologia Educacional. Rio de Janeiro: Aurora, 1957.

Introdução à Sociologia. 3. ed. Porto Alegre: Globo, 1961.

LÜDKE, Menga; ANDRÉ, Marli. Pesquisa em Educação: abordagens Qualitativas: São Paulo: EPU, 1986.

GHIRALDELLI, Paulo. História da Educação. São Paulo: Cortez, 1991.

MAIO, Marcos Chor e VILLAS BÔAS, Glaucia (orgs.). Idéias de Modernidade e Sociologia no Brasil. Ensaios sobre Luiz de Aguiar Costa Pinto. Porto Alegre: Editora da UFRGS, 1999.

MACIEL, Lizete Shizue Bomura; VIEIRA, Renata de Almeida; SOUZA, Fátima Cristina Lucas de. Afro do Amaral Fontoura: Estudos, produções e a Escola Viva. Revista HISTEDBR on-line, Campinas, n. 47, p. 232-250, 2012. 
MAGALHÃES, Justino. O Manual Escolar no Quadro da História Cultural: para uma historiografia do manual escolar em Portugal. Revista SÍSIFO, n. 1, dez, 2006. Disponível em: 〈http://sisifo.fpce.ul.pt/?r=1\&p=6>. Acesso em março de 2014.

MEUCCI, Simone. A Institucionalização da Sociologia no Brasil: os primeiros manuais e cursos. 2000. 157 p. Dissertação (Mestrado em Sociologia). Intituto de Filosofia e Ciências Humanas da Universidade de campinas. São Paulo, 2000.

Os primeiros manuais didáticos de sociologia no Brasil. Estudos de Sociologia. São Paulo. v.6, n.10, p. 121-157, 2001.

. Sobre a Rotinização da Sociologia no Brasil: Primeiros Manuais Didáticos, seus autores, suas expectativas. Mediaçãos, Londrina, v.12, n.1, p. 31-66, jan/jun. 2007.

MICELI, Sergio. Intelectuais e classe dirigente no Brasil (1920-1945). São Paulo: Difel, 1979.

PEREZ, Cilmara Ferrari. A formação sociológica das normalistas nas décadas de 20 e 30. 2002. 208 p. Dissertação (mestrado em Educação). Faculdade de Educação da Universidade Estadual de Campinas. São Paulo, 2002.

PONTES, Heloísa. Retratos do Brasil: Editores, Editoras e "Coleção Brasiliana" nas Décadas de 30, 40 e 50. In: MICELI, Sérgio (org.). História das Ciências Sociais no Brasil. Volume I. São Paulo: Vértice: IDESP, 1989.

NAGLE, Jorge. Educação e sociedade na primeira república. São Paulo, Editora Pedagógica e Universitária, Rio de Janeiro, Fundação Nacional do Material escolar, 1976.

SAVIANI, Dermeval. História das ideias pedagógicas no Brasil. Campinas, SP: Autores Associados, 2010.

SARANDY, Flávio Marcos Silva. A sociologia volta à escola: um estudo dos manuais de sociologia para o ensino médio no Brasil. Dissertação de mestrado. (Pós-Graduação em Sociologia e Antropologia) Universidade Federal do Rio de Janeiro (UFRJ), Rio de Janeiro, set. 2004.

SERRY, Hervé. Saint Thomas Sociologue? Les enjeux cléricaux d'una sociologie catholique dans les années 1880-1920. Actes de la Recherche en Sciences Sociales. $2004 / 3$ (nº153). p. $28-40$.

VIÑAO, Antonio. A história das disciplinas escolares. Revista Brasileira História da Educação, n. 18, p. 173-208, 2008. 


\section{Notas}

*Licenciado em Ciências Sociais - UFPel; Mestrando em Educação - UFPel; Professor de Sociologia IFSUL

${ }^{1}$ Conforme o dicionário Aurélio (2008, p. 154) compêndio significa "livro para escolas". Também pode ser interpretado como um manual didático para o ensino de uma disciplina.

${ }^{2}$ Este artigo é uma versão melhorada de um trabalho apresentado no $19^{a}$ ASPHE (Associação Sulriograndense de Pesquisadores em História da Educação) realizado em Pelotas/RS entre os dias 06 a 08 de novembro de 2013. Gostaria de deixar aqui meus sinceros agradecimentos a professora Anne Marie Wautier - professora de sociologia do curso de Ciências Sociais - UFPel, pela leitura atenta, e crítica construtiva do presente trabalho. Também agradeço a Juncris Namaya Junior - acadêmico de Arquitetura e Urbanismo UFPel pela tradução do resumo.

${ }^{3}$ Ver em anexo descrição dos pontos, ou capítulos.

${ }^{4}$ Luiz de Aguiar Costa Pinto foi um sociólogo brasileiro, com atuação nos anos 1950 e 60 nas áreas desociologia rural, desenvolvimento sócio-econômico e relações raciais. Seus trabalhos repercutiram no Brasil e no exterior e são considerados uma das bases do pensamento social brasileiro contemporâneo.Ver mais em: MAIO, Marcos Chor e VILLAS BÔAS, Glaucia (orgs.). Idéias de Modernidade e Sociologia no Brasil. Ensaios sobre Luiz de Aguiar Costa Pinto. Porto Alegre: Editora da UFRGS, 1999.

${ }^{5}$ Para Amaral Fontoura "postulado é uma verdade idemostrável, é uma verdade evidente". (1944, p. 135).

${ }^{6}$ Associação Brasileira de Educação surgiu em outubro de 1924 por iniciativa de 13 intelectuais cariocas. Embora na origem o grupo tivesse a intenção de organizar um "partido do ensino", a ABE firmou-se como órgão apolítico, destinado a congregar todos os interessados na causa da educação, independentemente de doutrinas filosóficas ou religiosas ou de posições políticas. (SAVIANI, 2010, p. 229).

7 “Qualis é o conjunto de procedimentos utilizados pela Capes para estratificação da qualidade da produção intelectual dos programas de pós-graduação. Tal processo foi concebido para atender as necessidades específicas do sistema de avaliação e é baseado nas informações fornecidas por meio do aplicativo Coleta de Dados. Como resultado, disponibiliza uma lista com a classificação dos veículos utilizados pelos programas de pós-graduação para a divulgação da sua produção." Disponível em <http://www.capes.gov.br/avaliacao/qualis>. Acesso em 27 de março de 2013.

${ }^{8}$ Trata-se do artigo intitulado "Aspectos históricos da cadeira de sociologia nos estudos secundários (18921925)." Autoria de Eva Maria Alves e Patrícia Costa, publicado pela Revista Brasileira de História da Educação. Disponível em 〈http://www.rbhe.sbhe.org.br >.

${ }^{9}$ Sobre o assunto consultar: AMARAL, Giana Lange. Gymnasio Pelotense e a Maçonaria; uma face da história da educação em Pelotas. 1. ed. Pelotas: Seiva publicações, 1999.

Recebido: novembro-13 Aprovado: abril-14 